Check for updates

Kent, UK

Cite this as: $B M J 2021 ; 375: n 2508$ http://dx.doi.org/10.1136/bmj.n2508 Published: 14 October 2021

\title{
Emphasising the health benefits of climate change actions can make them more attractive to governments, says scientists
}

Jacqui Wise

Taking action on the climate crisis is a "win-win" as it will also produce positive impacts on health, according to a report from the Academy of Medical Sciences and the Royal Society. ${ }^{1}$

A Healthy Future: Tackling Climate Change Mitigation and Human Health Together urges the UK government to ensure that health benefits are put at the heart of climate change discussions at the forthcoming COP26 meeting in Glasgow. It says emphasising the benefits to health of climate change measures can produce additional incentives for governments to act and increase public support.

The report echoes the message of a recent World Health Organization report and open letter signed by hundreds of health organisations from around the world which called on countries to step up action against climate change. ${ }^{2}$

The latest report brought together 11 leading experts to review the evidence of how climate change mitigation actions could promote human health in the near term, through co-benefits. Actions to phase out fossil fuels, develop more energy efficient housing, promote healthier dietary choices, and encourage more walking and cycling can all simultaneously benefit human health and accelerate progress towards the UK target of net zero greenhouse gas emissions by 2050.

Andy Haines, co-chair of the report and professor of environmental change and public health at London School of Hygiene and Tropical Medicine, told a Science Media Centre briefing, "The report gives a number of 'win-win' examples of actions that would have both a positive impact on health and the climate. Many of the measures, such as improved public transport access, improving diets, and energy efficient housing, could also help decrease health inequalities."

He added, "This double messaging is quite powerful. Emphasising the benefits to both health and climate may make these messages more attractive and more likely to be acted on.”

For example, air pollution causes between 28000 and 36000 premature deaths a year in the UK, many of which could be prevented by phasing out fossil fuels. Increased daily walking and cycling in urban England and Wales-similar to the levels in Copenhagen-could reduce heart disease, stroke, diabetes, and other diseases with potential savings to the NHS of $€ 17$ bn over 20 years. Consuming a healthy diet containing reduced red and processed meats and increased fruits and vegetables is projected to increase average life expectancy by about eight months and reduce food related greenhouse gas emissions by around $17 \%$.
Lorraine Whitmarsh, director of the Centre for Climate Change and Social Transformations, University of Bath, said, “Technology alone will not fix climate change, we need significant behavioural change. We need to bring people with us." She added that the message that climate change action can produce benefits for health has not yet filtered through to the public.

The report noted that the impact of climate change mitigation strategies was mainly positive, however there could also be unintended negative effects on health. For example, a move to greater reliance on batteries means more cobalt needs to be mined, which may have health disadvantages for the communities involved. It also calls for climate change initiatives to be robustly and regularly monitored for their impacts on health. It says that researchers from different disciplines should work together to tackle the complex interaction between climate change mitigation and health.

Academy of Medical Societies and Royal Society. A healthy future: tackling climate change mitigation and human health together. October 2021. https://acmedsci.ac.uk.

2 Wise J.WHO and the global health community call for urgent action on the climate crisis. BMJ 2021;375. 